\title{
A Model Calculation of Step-Flow Growth on Single-Layer Stepped Diamond (001) Surface
}

\author{
Takashi Yanagihara*, Daisuke Kodama and Masahiro Kato ${ }^{*}$ \\ Department of Materials Chemistry and Engineering, College of Engineering, Nihon University, Koriyama, Fukushima \\ 963-8642, Japan
}

\begin{abstract}
Step-flow growths of diamond on single-layer steps of hydrogenated diamond (001) surface have been investigated using the semiempirical molecular orbital method PM5. The chemical reactions at the first stage of growth have been calculated as a function of the charges biased to the substrates. When the frontier orbits of a pair of surface hydrogen atoms of step edge by negative charge -2 interact effectively with frontier orbits of hydrogen gases, the pair of surface hydrogen atoms is abstracted by two hydrogen gases. A dimer $\mathrm{C}_{2}$ is bonded onto the pair of vacant hydrogen sites by the chemisorption. The step-flow growth of the dimer rows seem to be proceeded by $\mathrm{C}_{2}$ under the influence of a pulsed charge ( -2 and 0$)$ biased to the single-layer stepped (001) surface.
\end{abstract}

Keywords: Model caluculation, diamond film, step-flow growth, single-layer step, semiemprirical molecular orbital method, dimer row, pulsed charge.

\section{INTRODUCTION}

The growth of diamond films by chemical vapor deposition (CVD) has important role for their potential application in electronic and optical devices. High-quality diamond films with atomically flat surface and low defect density are further required for the electronic device applications. Diamond homoepitaxial films on (001) substrates exhibited better quality than those on (110) and (111) substrates [1-3].

Tsuno et al. studied with scanning tunneling microscopy (STM) and reflection high-energy electron diffraction (RHEED) observations of homoepitaxial diamond layer grown on the diamond (001) surfaces by microwave plasma CVD (MPCVD) using $\mathrm{CH}_{4}\left(6 \% Y \mathrm{H}_{2}\right.$ at $830^{\circ} \mathrm{C}$ [4]. The RHEED pattern exhibited $2 \times 1$ and $1 \times 2$ dimer structures along the (110) direction. The images of the atomic level corresponding to the RHEED pattern were obtained by STM. The direction of the dimer rows in an area was perpendicular to those in other area, which was lower than the former area by $0.9 \AA$ of a monatomic step. The homoepitaxial growth of the (001) diamond films has mainly been performed in a step-flow growth mode [4-6]. The more detailed STM images of $(001) 2 \times 1$ dimer rows gave the homoepitaxial diamond (001) layer grown using $\mathrm{CO}(5 \%) \mathrm{H}_{2}$ by Kawarada et al. [7]. Tsuno et al. proposed the following models for the growth on diamond (001) substrates [8]. First, the growth with $\mathrm{CH}_{4}(2 \%) \mathrm{H}_{2}$ depended on the step flow in the small rate of two-dimension nucleation. Second, the rate of twodimensional nucleation increased with the increase of methane concentration, $\mathrm{CH}_{4}(6 \%) \mathrm{H}_{2}$. The step-flow growth

*Address correspondence to these authors at the Department of Materials Chemistry and Engineering, College of Engineering, Nihon University, Koriyama, Fukushima 963-8642, Japan; Tel: +81-24-956-8816/+81-24-9568813; Fax:+81-24-956-8862/+81-24-956-8862;

E-mails: yanagiha@ge.ce.nihon-u.ac.jp,mkatoh@chem.ce.nihon-u.ac.jp process has not yet been determined clearly. Theoretical studies are required for developing perfect crystal quality.

By the model calculation of semi empirical molecular orbital methods, Yanagihara asserted that $\mathrm{CH}$ and $\mathrm{CH}_{2}$ adsorbed on a vacant $\mathrm{H}$ site of the hydrogenated diamond (111) surface exerted positive influence on homoepitaxial growth by the application of a pulsed negative charge $(-1)$ or an alternating charge $(-1$ and +1$)$ bias to the substrate [9]. The adsorptions of $\mathrm{CH}$ and $\mathrm{CH}_{2}$ onto the diamond (111) surface had determined by using the nucleation theory. The experimental studies suggested that the charges required for the growth were given by plasma [10]. Mehandru and Anderson further obtained stable monolayer $\mathrm{CH}_{2}$ chemisorption and observed that the $\mathrm{CH}_{2}$ easily picked up a $\mathrm{H}$ gas to form a $\mathrm{CH}_{3}$ during the diamond growth process [11]. Yanagihara furthermore suggested that $\mathrm{CH}$ and $\mathrm{CH}_{2}$ adsorbed on the $\{111\}$ B surfaces of c-BN exerted positive influence on the nucleation by positive charge biased [12]. The abstractions of the surface $\mathrm{H}$ atom on the $\{111\} \mathrm{N}$ surfaces are however impeded because frontier orbitals of the surface $\mathrm{H}$ atom interacted less effectively with frontier orbitals of the $\mathrm{H}$ gases. Based on their results, they suggested that nucleation on the $\{111\} \mathrm{N}$ surfaces did not proceed. The results corresponded to ones of the heteroepitaxial diamond growth on the $\{111\}$ surfaces of c-BN using d.c. plasma CVD by Koizumi and Inuzuka [13]. That is, the boronterminated $\{111\}$ B surfaces were all covered with diamond film, while such deposition hardly occurred on nitrogenterminated $\{111\} \mathrm{N}$ surfaces.

For diamond films growth on the $(001) 2 \times 1$ surface, Garrison el al. [14] had suggested that $\mathrm{CH}_{2}$ radicals were highly reactive and important for growth. But, our calculated results have deduced that dimers, $\mathrm{C}_{2}$, are important for the step-flow growth of diamond (001) surface by using nucleation theory and a frontier orbital theory $[9,12]$. 


\section{CALCULATING METHODS}

The PM5 approximation of MOPAC 2002 for semiempirical molecular orbital calculations was used for solving the Schrödinger equation at the Hartree-Fock level in the quantum chemical optimization of atomic cluster geometry $[9,15,16]$. In modeling the crystal structure, this approximation is appropriate for the calculations of geometric optimization of large clusters formed with numerous atoms in a short time.

Fig. (1) shows a model of a diamond cluster $\mathbf{M}_{1}$, $\mathrm{C}_{173} \mathrm{H}_{104}$, with a stepped hydrogenated (001) face bound by four $\{111\}$ faces. The large gray and small black balls respectively represent carbon and hydrogen atoms. The $\mathrm{H}$ monohydride phase has been assumed except for the edge sites $\{111\}$ and vacant hydrogen atom sites. The starting species $\mathbf{M}_{1}$ has been used in the growth mechanism. The calculations can be used to discuss only the reactions over the barrier of activation energy at $1200 \mathrm{~K}$.

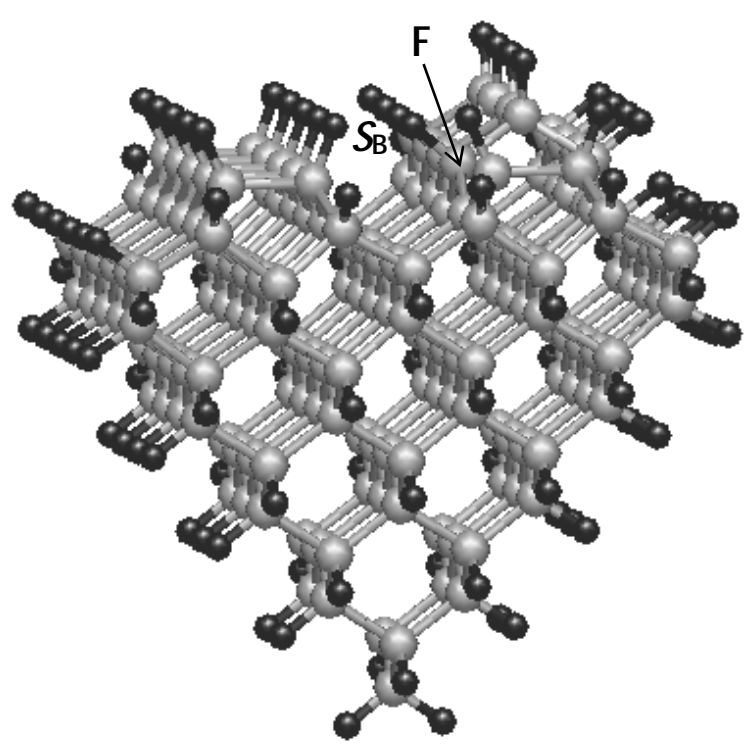

Fig. (1). Model of diamond cluster $\mathbf{M}_{1}, \mathrm{C}_{173} \mathrm{H}_{104}$, with a stepped hydrogenated (001) face bound by four $\{111\}$ faces.

Regarding diamond growth by CVD in a $\mathrm{CH}_{4} / \mathrm{H}_{2}$ gas mixture, both the abstractions of the surface $\mathrm{H}$ atoms and the chemisorption by a radical gas on the substrate are important. In the present study, the growth for the chemisorption is slowly in comparison with the one by Van der Waals' forces $[9,17]$. First, the pair of surface $\mathrm{H}$ atoms is abstracted by $2 \mathrm{H}$ gases and the pair vacant $\mathrm{H}$ atom sites are produced. Next, radical gases bond onto the vacant $\mathrm{H}$ atom sites. The relative stability of the cluster structures in these models has been estimated on the basis of the heat of formation (HOF) obtained by PM5 calculations.

A chemical interaction between the gas and the cluster surface during diamond growth by CVD has been analyzed based on the electronic energy levels of the interacting fragments of cluster and gas molecules $[9,18]$. The interactions between the two systems are pair wise additive over the molecular orbital each pair interaction as follows:

$\Delta E=\left|H_{\mathrm{ij}}\right|^{2} /\left(E_{\mathrm{i}}-E_{\mathrm{j}}\right)$,

where $H_{\mathrm{ij}}$ is proportional to the overlap integral and the eigenvectors (coefficients) of the atomic orbitals in the molecular orbitals, $\mathrm{i}$ and $\mathrm{j}$, for the interaction. $\left(E_{\mathrm{i}}-E_{\mathrm{j}}\right)$ denotes the difference in energy of the molecular orbitals $i$ and $\mathrm{j}$.

Assuming the quasi-equilibrium, the formation probabilities of the products from the reactants at temperature $\mathrm{T}$ are obtained as follows. The existence of gases $\mathrm{k}$ and 1 of number density $n_{\mathrm{k}}$ and $n_{1}$ is assumed on the surface of a cluster. Giving the formation probabilities of the clusters $\mathbf{K}$ and $\mathbf{L}$ for the gases $\mathrm{k}$ and 1 on the surface of a cluster $\mathbf{M}$ by $P_{\mathrm{K}}$ and $P_{\mathrm{L}}$,

$P_{\mathrm{L}} / P_{\mathrm{K}}=n_{1} / n_{\mathrm{k}} \cdot \exp \left[\left(G_{\mathrm{K}}-G_{\mathrm{L}}\right) / \mathrm{kT}\right]$.

where, $G_{\mathrm{K}}$ and $\epsilon_{\mathrm{L}}$ are the binding energies of the gases $\mathrm{k}$ and 1 bonded with the cluster $\mathbf{M}$, respectively. The surface diffusion energies of the radical gases are excluded in Eq. (2) because these are very small compared with the binding energies.

The binding energy $G_{\mathrm{K}}$ is given by

$\epsilon_{\mathrm{K}}=\Delta H_{\mathrm{f}}(\mathbf{K})-\left[\Delta H_{\mathrm{f}}(\mathbf{M})+\Delta H_{\mathrm{f}}(\mathrm{k})\right]$,

where, $\Delta H_{\mathrm{f}}(\mathbf{K})$ and $\Delta H_{\mathrm{f}}(\mathbf{M})$ represent the HOFs in the clusters $\mathbf{K}$ and $\mathbf{M}$, respectively. As the HOF, $\Delta H_{\mathrm{f}}(\mathrm{k})$, for gas $\mathrm{k}$, we have used the standard HOFs for gases [9].

\section{STEP-FLOW GROWTH OF DIAMOND ON STEPPED DIAMOND (001) SURFACE}

\section{a) Growth of Diamond on the Single-Layer $S_{B}$ of "Nonbonded" Edge}

A diamond cluster model $\mathbf{M}_{1}, \mathrm{C}_{173} \mathrm{H}_{104}$, with the stepped hydrogenated (001) face bound by four hydrogenated $\{111\}$ faces is shown in Fig. (1). Atom marked (F) is the carbon atom at the kink site. The (001) surface is composed by the two single-layer $S_{\mathrm{A}}$ and $S_{\mathrm{B}}$ steps, as shown in Fig. (2a). Large shaded and gray circles represent carbon atoms on the upper-terrace and lower-terrace, respectively. The subscripts, $\mathrm{A}$ and $\mathrm{B}$, respectively denote as normal and parallel to the step edge for the dimerization direction of the carbon atoms on an upper terrace near a step [19]. The $S_{\mathrm{B}}$ step has also simple "nonbonded" edge geometry. The $S_{\mathrm{A}}$ and $S_{\mathrm{B}}$ steps compose a kink site $(\mathbf{F})$ at these boundaries. The model has been used as the starting species in the growth mechanism.

The relative energies for HOFs of four clusters are shown as a function of the charges biased to the clusters in Table $\mathbf{1 .}$ $\mathbf{P}_{1}, \mathrm{C}_{173} \mathrm{H}_{102}$, has a pair of vacant $\mathrm{H}$ atom sites on two carbon sites (F) and (G) along the stepped edge of $S_{\mathrm{B}}$, as shown in Fig. (2a). $\mathbf{P}_{1} \cdot \mathrm{C}_{2}$ and $\mathbf{P}_{1} \cdot \mathrm{C}_{2} \mathrm{H}_{2}$ are the clusters with $\mathrm{C}_{2}$, and $\mathrm{C}_{2} \mathrm{H}_{2}$ bonded onto the pair of vacant $\mathrm{H}$ atom sites $(\mathrm{F})$ and (G), respectively. The abstraction of the surface $\mathrm{H}$ atoms from the neutral surface of the stable $\mathbf{M}_{1}(0)$ is impeded by the high barrier of $462 \mathrm{~kJ} / \mathrm{mol}\left(1 \mathrm{~kJ} / \mathrm{mol}=1.036 \times 10^{-2} \mathrm{eV}\right)$.

The reactions of radical gases and the surface $\mathrm{H}$ atoms of the stepped (001) diamond surfaces are given by Eq. (1). The HOF of $\mathbf{M}_{1}(2-)$ of a negative charge -2 biased to the substrate becomes $-1105 \mathrm{~kJ} / \mathrm{mol}$ for the geometric meta- 


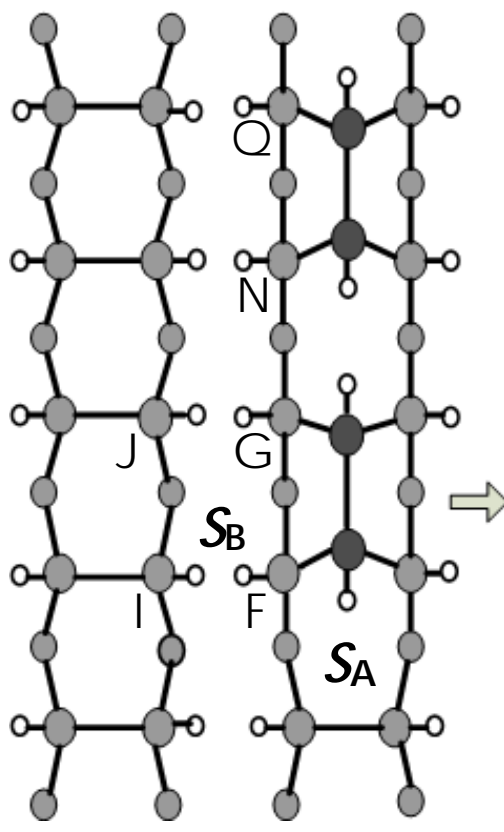

(a)

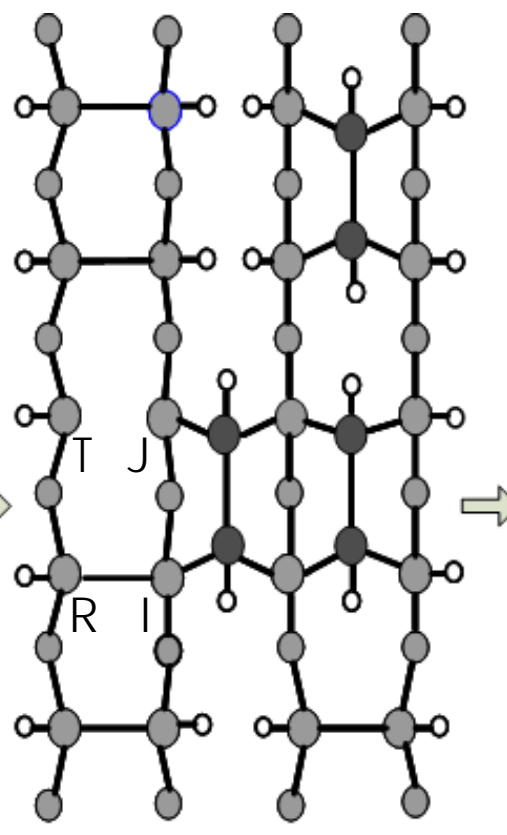

(b)

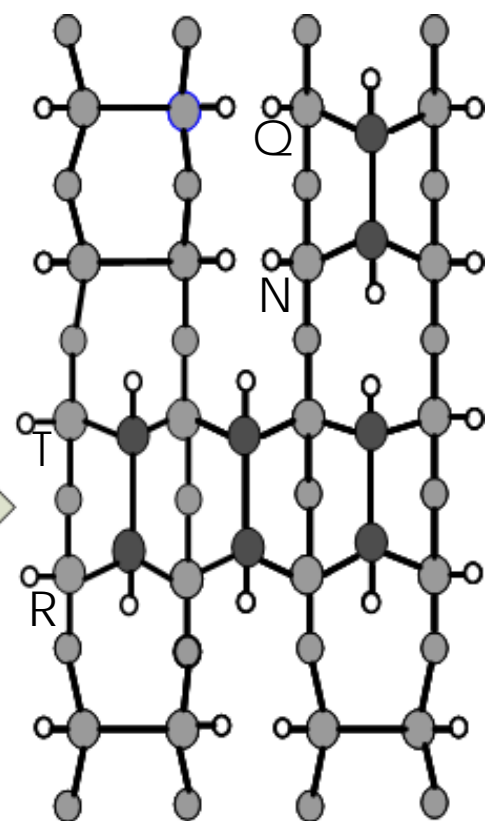

(c)

Fig. (2). A top view model for the extension of single dimer row on (001) surface.

stable state. The surface $\mathrm{H}$ atoms on the carbon sites $(\mathrm{F})$ and (G) of $\mathbf{M}_{1}$ (2-) in Fig. (2a) are relatively large total electronic densities 0.021 and 0.033 in the high occupier molecular orbitals of $-4.39 \mathrm{eV}$ and $-3.94 \mathrm{eV}$, respectively. The electrons are effectively interacted with the electron energy level, $3.40 \mathrm{eV}$, at $\mathrm{n}=2$ of a gas of $\mathrm{H}$ atoms. A pair of surface $\mathrm{H}$ atoms is therefore abstracted from the surface by $2 \mathrm{H}$ gases and $\mathbf{M}_{1}(2-)$ becomes to the cluster $\mathbf{P}_{1}(2-)$ with a pair of vacant $H$ sites. The binding energy of two surface $H$ atoms on the carbon sites $(F)$ and $(G)$ of $\mathbf{M}_{1}(2-)$ is $-240 \mathrm{~kJ} / \mathrm{mol}$, as shown in Table 2. Comparing with the binding energy of the surface $H$ atoms on the flat (001) $2 \times 1$ surface given a negative charge $-2,-317 \mathrm{~kJ} / \mathrm{mol}$, the present binding energy is considerably small. The negative charge given to $\mathbf{M}_{1}(2-)$ distributes widely over the whole structure. In the cluster $\mathbf{P}_{1}(2-)$, the negative charge of -2 compensates the charges of two dangling bonds on the two surface vacant $\mathrm{H}$ sites $(\mathrm{F})$ and $(\mathrm{G})$, and the whole structure is stabilized by the abstractions. HOF of $\mathbf{P}_{1}(2-)$ becomes the stable state of $-1301 \mathrm{~kJ} / \mathrm{mol}$ (Table 1).

Table 1. Heat of Formation (HOF) Calculated as a Function of the Charges for Clusters

\begin{tabular}{|c|c|c|c|c|}
\hline \multicolumn{5}{|c|}{ Energy for HOF $(\mathbf{k J} / \mathbf{m o l})$} \\
\hline \multirow{3}{*}{ Cluster } & \multicolumn{4}{|c|}{ Charge Given to Cluster } \\
\cline { 2 - 5 } & $\mathbf{0}$ & $\mathbf{- 2}$ & $-\mathbf{4}$ & $\mathbf{2}$ \\
\hline \hline $\mathrm{M}_{1}\left(\mathrm{C}_{173} \mathrm{H}_{104}\right)$ & -1742 & -1105 & 256 & -42 \\
$\mathrm{P}_{1}\left(\mathrm{C}_{173} \mathrm{H}_{102}\right)$ & -1280 & -1301 & 43 & -20 \\
$\mathrm{P}_{1} \cdot \mathrm{C}_{2}$ & -958 & -933 & 377 & 699 \\
$\mathrm{P}_{1} \cdot \mathrm{C}_{2} \mathrm{H}_{2}$ & -1461 & -1042 & - & 193 \\
\hline
\end{tabular}

Table 2. Binding Energy Calculated by Eq. (3) for $2 \mathrm{H}, \mathrm{C}_{2}$, and $\mathrm{C}_{2} \mathrm{H}_{2}$ on the Cluster $\mathrm{P}_{1}$

\begin{tabular}{|c|c|c|c|c|}
\hline \multicolumn{5}{|c|}{ Binding Energy $\boldsymbol{\epsilon}_{\mathbf{K}}(\mathbf{k J} / \mathbf{m o l})$} \\
\hline \multirow{2}{*}{ Gas } & \multicolumn{4}{|c|}{ Charge given to cluster } \\
\cline { 2 - 5 } & $\mathbf{0}$ & $-\mathbf{2}$ & $-\mathbf{4}$ & $\mathbf{2}$ \\
\hline \hline $2 \mathrm{H}$ & -898 & -240 & -223 & -458 \\
$\mathrm{C}_{2}$ & -516 & -470 & -504 & -119 \\
$\mathrm{C}_{2} \mathrm{H}_{2}$ & -408 & 32 & - & -14 \\
\hline
\end{tabular}

When $2 \mathrm{H}$ gases by an exothermic reaction remove a pair of surface $\mathrm{H}$ atoms from two carbon sites of the cluster $\mathbf{M}_{1}(2-)$, the heats of reaction, $\Delta H$, for the abstraction of the pair of surface $\mathrm{H}$ atoms at $298 \mathrm{~K}$ are calculated as a function of charge. The cluster $\mathbf{P}_{1}(2-)$ with a pair vacant $\mathrm{H}$ atoms on the sites (F) and (G) are produced; $\mathbf{M}_{1}(2-)+$ $2 \mathrm{H}=\mathbf{P}_{1}(2-)+2 \mathrm{H}_{2}(\Delta H=-632 \mathrm{~kJ} / \mathrm{mol})$. Also, the heats of reaction for $\mathrm{C}_{2}$ in the abstraction of two surface $\mathrm{H}$ atoms show the great value of $-807 \mathrm{~kJ} / \mathrm{mol}$. When the step-flow growth is dominant in the growth with $\mathrm{CH}_{4}(2 \%) / \mathrm{H}_{2}$, the concentration of $\mathrm{C}_{2}$ is the smaller quantity than $2 \%$ [4]. As the concentration is proportional to the reaction rate, the reaction rate of $2 \mathrm{H}$ is very higher than $\mathrm{C}_{2} .2 \mathrm{H}$ radical gases are therefore supposed the larger contribution than $C_{2}$ for the abstraction of a pair surface $\mathrm{H}$ atoms from $\mathbf{M}_{1}(2-)$.

In $\mathbf{M}_{1}$ (4-) given negative charge of -4 , a pair of surface $\mathrm{H}$ atoms on the carbon sites $(F)$ and $(G)$ is abstracted by $2 \mathrm{H}$ gases. $\mathbf{M}_{1}(4-)$ is transformed to $\mathbf{P}_{1}(4-)$. The binding energy of the surface $\mathrm{H}$ atoms is the small value of $-223 \mathrm{~kJ} / \mathrm{mol}$. As the binding energy of the surface $\mathrm{H}$ atoms on the carbon sites 
(N) and (Q) of $\mathbf{P}_{1}(4-)$ increases to $-408 \mathrm{~kJ} / \mathrm{mol}$, the surface $\mathrm{H}$ atoms are not abstracted by $2 \mathrm{H}$ gases. The dangling orbits of the vacant sites $(\mathrm{F})$ and $(\mathrm{G})$ of $\mathbf{P}_{1}(2-)$ have the very large total electron densities 1.44 and 1.44 at the highest occupier molecular orbital (HOMO) of $0.51 \mathrm{eV}$, respectively. The orbits interact effectively with the lowest unoccupied molecular orbital (LUMO) $-0.04 \mathrm{eV}$ of $\mathrm{C}$ atomic gas by Eq.(1). The kink site (F) has also the highest surface diffusion density of $\mathrm{C}$ gases and the highest reaction rate. In this model calculation, $2 \mathrm{C}$ gases on the sites $(\mathrm{F})$ and $(\mathrm{G})$ change instantaneously to $\mathrm{C}_{2}$ by the large binding energy of $598 \mathrm{~kJ} / \mathrm{mol}$ and become to the cluster $\mathbf{P}_{1}(2-) \cdot \mathrm{C}_{2}$. The HOF of $\mathbf{P}_{1}(2-) \cdot \mathrm{C}_{2}$ is $-933 \mathrm{~kJ} / \mathrm{mol}$ at the meta-stable state, as shown in Table 1. The binding energy between the $C_{2}$ and $\mathbf{P}_{1}(2-)$ gets $-470 \mathrm{~kJ} / \mathrm{mol}$ by Eq. (3) using $\mathrm{HOF}$ of $\mathrm{C}_{2}, 838 \mathrm{~kJ} / \mathrm{mol}$ [9]. The $\mathrm{C}_{2}$ on $\mathbf{P}_{1}(2-)$ changes to $\mathrm{C}_{2} \mathrm{H}_{2}$ by the abstraction of the two surface $\mathrm{H}$ atoms from the carbon sites (I) and $(\mathrm{J})$ on the lower terrace and $\mathbf{P}_{1}(2-) \cdot \mathrm{C}_{2}$ becomes to $\mathbf{P}_{1}{ }^{\prime}(2-) \cdot{ }^{\cdot} \mathrm{C}_{2} \mathrm{H}_{2}$. The negative charge -2 biased to the substrate is localized at the four carbons, $(\mathrm{F}),(\mathrm{G}),(\mathrm{I})$, and $(\mathrm{J})$, and these carbons repel each other. The $\mathrm{C}_{2} \mathrm{H}_{2}$ on the neutral surface of $\mathbf{P}_{1}{ }^{\prime}(0) \cdot \mathrm{C}_{2} \mathrm{H}_{2}$ forms a bridge bonded on the two vacant $\mathrm{H}$ atom sites of (I) and $(\mathrm{J})$ and the cluster is shown as $\mathbf{M}_{2}(0)$ in Fig. (2b). In the case of $2 \mathrm{CH}$ on $\mathbf{P}_{1}(2-), 2 \mathrm{CH}$ gases become instantaneously to $\mathrm{C}_{2} \mathrm{H}_{2}$ by the binding energy $-961 \mathrm{~kJ} / \mathrm{mol}$. But, $\mathrm{C}_{2} \mathrm{H}_{2}$ can not bond onto these sites by small repulsion power of $32 \mathrm{~kJ} / \mathrm{mol}$.

When $G_{\mathrm{K}}$ and $G_{\mathrm{L}}$ are respectively the binding energies of $2 \mathrm{H}$ and $\mathrm{C}_{2}$ bonded onto the $\mathbf{P}_{1}(2-)$, the values of formation probabilities in the Eq. (2) at $1200 \mathrm{~K}$ have been calculated using the values of $G_{\mathrm{K}}$ and $G_{\mathrm{L}}$. The exponential factor in the ratios of the formation probabilities between $2 \mathrm{H}$ and $\mathrm{C}_{2}$ is $1 \times 10^{10}$. The values of $n_{1} / n_{\mathrm{k}}$ becomes smaller than $10^{-2}$ when $n_{\mathrm{k}}$ and $n_{1}$ are the number densities of $2 \mathrm{H}$ and $\mathrm{C}_{2}$, respectively. The formation probability of $\mathrm{C}_{2}$ bonded onto $\mathbf{P}_{1}(2-)$ is however greater than the others. These rough approximations are sufficient for determining of radicals for the contribution to the nucleation.

\section{b) Growth on the Single-Layer $S_{B}$ Step of "Rebonded" Edge}

The cluster $\mathbf{M}_{2}, \mathrm{C}_{175} \mathrm{H}_{102}$, with the single-layer $S_{\mathrm{B}}$ step of two "rebonded" edges, (I) and (J), grown from $\mathbf{M}_{1}$ is shown in Fig. (2b). In the calculation of the geometric optimization, the bond on the carbon sites $(\mathrm{J})$ and $(\mathrm{T})$ is broken by a negative charge -2 biased to the substrate, and $\mathbf{M}_{2}(2-)$ becomes to the meta-stable state at the HOF, $-971 \mathrm{~kJ} / \mathrm{mol}$. The two carbons of $(\mathrm{J})$ and $(\mathrm{T})$ have the large electron densities of 0.235 and 0.508 at the HOMO of $1.12 \mathrm{eV}$, respectively. The two carbons of (I) and (R) respectively are also relatively large electron densities of 0.079 and 0.062 at the high occupier molecular orbital of $-3.13 \mathrm{eV}, \mathrm{C}_{2}$ formed by binding of $2 \mathrm{C}$ on the sites, $(\mathrm{J})$ and $(\mathrm{T})$, makes a bridge onto the carbon sites, (J), (T), (I), and (R). $\mathrm{C}_{2}$ onto the $\mathbf{M}_{2}(2-$ ) has a large binding energy of $-875 \mathrm{~kJ} / \mathrm{mol}$. The bridge, $\mathrm{C}_{2}$, on the neutral surface $\mathbf{M}_{2}(0)$ picks up $2 \mathrm{H}$ gases by the binding energy of $-814 \mathrm{~kJ} / \mathrm{mol}$, and $\mathrm{C}_{2}$ changes into $\mathrm{C}_{2} \mathrm{H}_{2}$, as shown in Fig. (2c). $\mathbf{M}_{2}(0) \cdot \mathrm{C}_{2} \mathrm{H}_{2}$ of the neutral charge becomes the stable state. A single dimer row is proceeded by $\mathrm{C}_{2}$ under the influence of a pulsed charge ( -2 and 0$)$ biased to the stepped surfaces.
The experimental studies of diamond growth suggest that the charges are supplied by plasma. It is guessed that the pulsed charge necessary for growth is given when the plasma changes from the minus charge into the plus charge.

In the calculation of the geometric optimization, $\mathbf{M}_{2}(0)$ and $\mathbf{M}_{2}(2+)$ do not break the bond. In $\mathbf{M}_{2}(2+)$, the positive charge +2 biased to the substrate is localized on the surface hydrogen atoms. Here, $\mathbf{M}_{2} \cdot \mathrm{C}_{2} \mathrm{H}_{2}$ with the double-layer $D_{\mathrm{B}}$ step is remade to $\mathbf{M}_{3}$.

\section{c) Growth on the Double-Layer $D_{B}$ Step of "Nonbonded" Edge}

The cluster $\mathbf{M}_{3}, \mathrm{C}_{183} \mathrm{H}_{110}$, with double-layer $D_{\mathrm{B}}$ step of the dimerization direction on an upper terrace parallel to the step edge, is shown in Fig. (3). Atom marked (R) is the carbon atom at the kink site of $D_{\mathrm{B}}$ and $S_{\mathrm{A}}$ steps. Fig. (4) shows the cluster $\mathbf{P}_{3} \cdot \mathrm{C}_{2}$ with the dimer $\mathrm{C}_{2}$, (U) and (V), bonded on the double-layer $D_{\mathrm{B}}$ step of cluster $\mathbf{P}_{3}, \mathrm{C}_{183} \mathrm{H}_{108}$. The circles of large shadow and gray represent carbon atoms of dimer rows on the upper-terrace and lower-terrace, respectively. The total electronic densities of two surface $\mathrm{H}$ atoms on the carbon sites of $(\mathrm{R})$ and $(\mathrm{T})$ are relatively large 0.018 and 0.027 in the high occupier molecular orbitals of $4.10 \mathrm{eV}$ and $-3.50 \mathrm{eV}$, respectively. In $\mathbf{M}_{3}(2-)$, a pair of surface $\mathrm{H}$ atoms on the sites $(\mathrm{R})$ and $(\mathrm{T})$ has the binding energy of $-237 \mathrm{~kJ} / \mathrm{mol}$. If a pair of surface $\mathrm{H}$ atoms on the sites (R) and (T) is abstracted by $2 \mathrm{H}$ gases, $\mathbf{M}_{3}(2-)$ is transformed to $\mathbf{P}_{3}(2-)$ with a pair of vacant surface $\mathrm{H}$ atoms on the carbon sites $(\mathrm{R})$ and $(\mathrm{T})$. The heat of reaction of the abstraction of two surface $\mathrm{H}$ atoms is $628 \mathrm{~kJ} / \mathrm{mol}$. In $\mathbf{P}_{3}(2-)$, the given negative charge is localized on the dangling bonds of carbon sites (R) and (T). The total electron densities of $(\mathrm{R})$ and $(\mathrm{T})$ are also respectively very large 0.618 and 0.930 at $\mathrm{HOMO}, 0.44 \mathrm{eV} . \mathrm{C}_{2}$ formed by $2 \mathrm{C}$ gases on the sites $(\mathrm{R})$ and (T) is bonded onto the $\mathbf{P}_{3}(2-), \mathrm{C}_{183} \mathrm{H}_{108}$, by the binding energies of $-473 \mathrm{~kJ} / \mathrm{mol}$. The sites (U) and (V) of $\mathrm{C}_{2}$ in Fig. (4) are large negative charges of -0.62 and -0.53 , respectively. Two surface $\mathrm{H}$ atoms on the sites (W) and (X) of the lower terrace are positive charges 0.26 and 0.34 of about three times or more than the circumferential 'surface' $\mathrm{H}$ atoms, respectively. The coulomb interactions are therefore obviously among these four atoms. The $\mathrm{C}_{2}$ however cannot abstract the surface $2 \mathrm{H}$ atoms on the sites (W) and (X). The average of the distances between the $\mathrm{H}$ atoms and the carbons, $(\mathrm{U})$ and $(\mathrm{V})$, of $\mathrm{C}_{2}$ respectively is about $0.23 \mathrm{~nm}$ and it is longer than about $0.19 \mathrm{~nm}$ of $\mathbf{P}_{1} \cdot \mathrm{C}_{2}$. The $\mathrm{C}_{2}$ on the neutral surface easily picks up $4 \mathrm{H}$ gases with the large binding energy of $-1519 \mathrm{~kJ} / \mathrm{mol}$ and $\mathrm{C}_{2}$ becomes to $\mathrm{C}_{2} \mathrm{H}_{4}$. The $\mathrm{C}_{2} \mathrm{H}_{4}$ on $\mathbf{P}_{3}(2-) \cdot \mathrm{C}_{2} \mathrm{H}_{4}$ given a negative charge -2 is evaporated from the substrate by large repulsion power, $251 \mathrm{~kJ} / \mathrm{mol}$. Two vacant surface $\mathrm{H}$ sites $(\mathrm{R})$ and $(\mathrm{T})$ on the neutral surface of $\mathbf{P}_{3}(0)$ capture the $2 \mathrm{H}$ gases and comes back to $\mathbf{M}_{3}(0)$ of Fig. (3). The growth of the dimer row from $\mathbf{P}_{1}(2-) \cdot \mathbf{C}_{2}$ therefore stops at this stage. The growth of next dimer row then restarts from the carbon sites $(\mathrm{N})$ and $(\mathrm{Q})$ of two vacant surface $H$ atoms.

On the other hand, the binding energy of the surface $\mathrm{H}$ atoms on the sites $(\mathrm{N})$ and $(\mathrm{Q})$ is $-245 \mathrm{~kJ} / \mathrm{mol}$. If the surface $\mathrm{H}$ atoms are abstracted by $\mathrm{H}$ gases, $\mathbf{M}_{3}(2-)$ is transformed to $\mathbf{P}_{3}{ }^{\prime}(2-)$. Two vacant surface $\mathrm{H}$ atom sites (N) and (Q) 


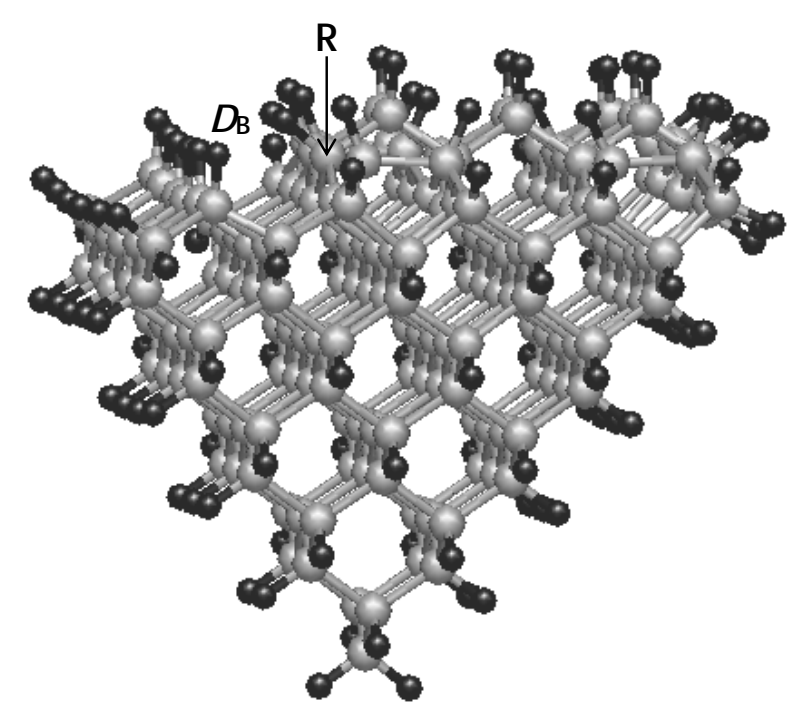

Fig. (3). Model of diamond cluster $\mathbf{M}_{3}, \mathrm{C}_{183} \mathrm{H}_{110}$, with a doublelayer $D_{\mathrm{B}}$ stepped hydrogenated $(001)$ face bound by four $\{111\}$ faces.

respectively are very large total electron densities 0.618 and 0.930 in the $\mathrm{HOMO}$ of $0.439 \mathrm{eV} . \mathrm{C}_{2}$ formed by $2 \mathrm{C}$ gases onto $(\mathrm{N})$ and $(\mathrm{Q})$ is bonded onto the $\mathbf{P}_{3}{ }^{\prime}(2-)$ by the binding energy of $-481 \mathrm{~kJ} / \mathrm{mol}$. The dimer rows from $\mathbf{P}_{3}{ }^{\prime}(2-) \cdot \mathrm{C}_{2}$ grow in the same way similar to the previous studies.

\section{CONCLUSIONS}

Step-flow growths of diamond on the single-layer steps of "nonbonded" edge and "rebounded" edge in the hydrogenated diamond (001) surface have been investigated using the semiempirical molecular orbital method PM5. The chemical reactions at the first stage of growth have been calculated as a function of the charges biased to the substrates. The hydrogenated diamond, $\mathbf{M}_{1}(2-)$, of a negative charge -2 biased becomes unstable. The surface $\mathrm{H}$ atoms are abstracted by $2 \mathrm{H}$ gases, $\mathbf{P}_{1}(2-) . \mathrm{C}_{2}$ formed by $2 \mathrm{C}$ atomic gases is bonded onto the vacant $\mathrm{H}$ atom sites, $\mathbf{P}_{1}(2-)^{\cdot} \mathrm{C}_{2}$. The $\mathrm{C}_{2}$ on the cluster changes to $\mathrm{C}_{2} \mathrm{H}_{2}$ by the abstraction of two surface $\mathrm{H}$ atoms on the lower terrace, $\mathbf{P}_{1}{ }^{\prime}(2-) \cdot \mathrm{C}_{2} \mathrm{H}_{2}$. The $\mathrm{C}_{2} \mathrm{H}_{2}$ on the neutral surface of $\mathbf{P}_{1}{ }^{\prime}(0) \cdot \mathrm{C}_{2} \mathrm{H}_{2}$ forms a bridge bonded with the two vacant $\mathrm{H}$ atom sites on the lower terrace and it becomes to $\mathbf{M}_{2}(0)$, as shown in Fig.(2b).

The cluster $\mathbf{M}_{2}$ with the single-layer $S_{\mathrm{B}}$ step of "rebounded" edge becomes unstable by the negative charges. The "rebounded" edge of $(\mathrm{J})$ and $(\mathrm{T})$ is broken by the charge -2 biased to the substrate. $\mathrm{C}_{2}$ formed by $2 \mathrm{C}$ gases on the broken bond sites makes the bridge bonded on the four carbon sites and $\mathbf{M}_{2}(2-)$ becomes $\mathbf{M}_{2}(2-) \cdot \mathbf{C}_{2}$. The $\mathrm{C}_{2}$ on the neutral surface picks up $2 \mathrm{H}$ gases and it changes to $\mathrm{C}_{2} \mathrm{H}_{2}$. $\mathbf{M}_{2}(0) \cdot \mathrm{C}_{2}$ becomes $\mathbf{M}_{2}(0) \cdot \mathrm{C}_{2} \mathrm{H}_{2}$ of stable state, as shown in Fig. (2c). When $\mathbf{M}_{2} \cdot \mathrm{C}_{2} \mathrm{H}_{2}$ meets to a double-layer $D_{\mathrm{B}}$ step, $\mathbf{M}_{3}$ of Fig. (3) is remade.

When a pair surface $\mathrm{H}$ atoms on the carbon sites $(\mathrm{R})$ and (T) of $\mathbf{M}_{3}(2-)$ is abstracted by $2 \mathrm{H}$ gases, $\mathrm{C}_{2}$ bonds on the vacant $\mathrm{H}$ atom sites and $\mathbf{M}_{3}(2-)$ become to $\mathbf{P}_{3}(2-) \cdot \mathrm{C}_{2}$ in Fig. (4). The $\mathrm{C}_{2}$ on $\mathbf{P}_{3}(2-) \cdot \mathrm{C}_{2}$ can not abstract the two surface $\mathrm{H}$ atoms of the lower terrace. The $\mathrm{C}_{2}$ on the neutral surface picks up $4 \mathrm{H}$ gases and $\mathrm{C}_{2}$ changes to $\mathrm{C}_{2} \mathrm{H}_{4}$. The $\mathrm{C}_{2} \mathrm{H}_{4}$ on
$\mathbf{P}_{3}(2-) \cdot \mathrm{C}_{2} \mathrm{H}_{4}$ given a negative charge of -2 is evaporated by large repulsion power. The two vacant surface $H$ sites, $(R)$ and $(\mathrm{T})$, on the neutral surface of $\mathbf{P}_{3}(0)$ capture $2 \mathrm{H}$ gases and $\mathbf{P}_{3}(0)$ returns to $\mathbf{M}_{3}(0)$. The growth of the dimer row from $\mathbf{P}_{1}(2-) \cdot \mathrm{C}_{2}$ therefore stops here.

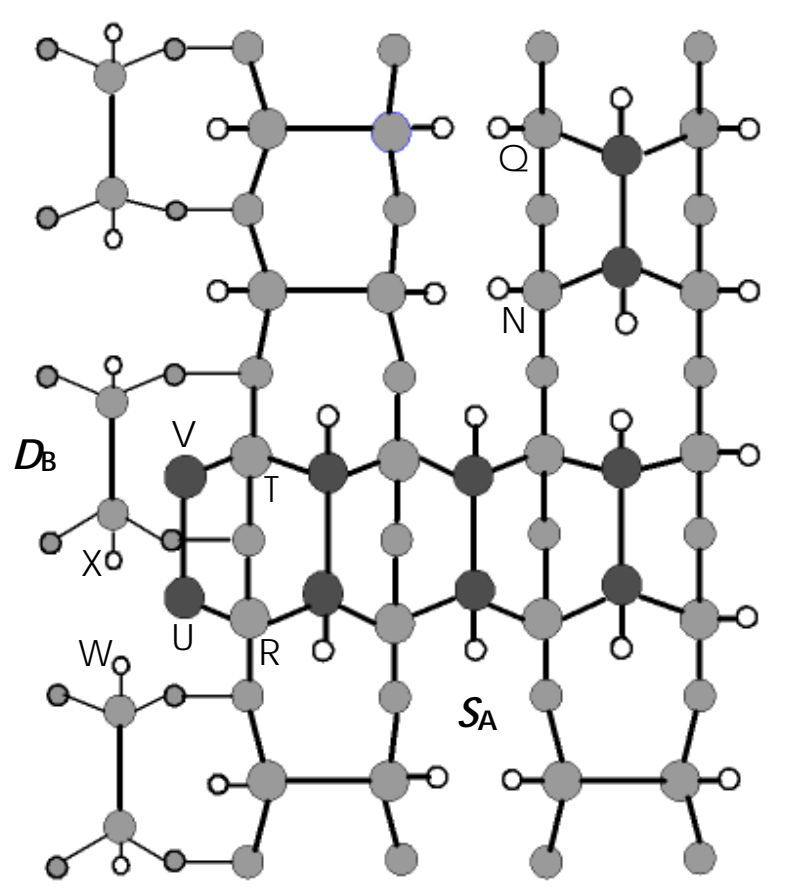

Fig. (4). A top view model of cluster $\mathbf{P}_{3} \cdot C_{2}$ with the dimer $\mathrm{C}_{2}$, (U) and $(\mathrm{V})$, bonded on the double-layer $D_{\mathrm{B}}$ step of cluster $\mathbf{P}_{3}, \mathrm{C}_{183} \mathrm{H}_{108}$.

If a pair surface $\mathrm{H}$ atoms on the sites $(\mathrm{N})$ and $(\mathrm{Q})$ in Fig. (4) is abstracted by $2 \mathrm{H}$ gases, $\mathbf{M}_{3}(2-)$ is transformed to $\mathbf{P}_{3}$ '(2) with a vacant surface $\mathrm{H}$ sites. $\mathrm{C}_{2}$ bonds on the vacant $\mathrm{H}$ atom sites and the dimer row grow in the same way as $\mathbf{M}_{1}$. We have therefore deduced that the step-flow growth of the dimer rows is proceeded by $\mathrm{C}_{2}$ under the influence of a pulsed charge ( -2 and 0 ) biased to the stepped surfaces.

The calculation has excluded the single-layer $S_{\mathrm{A}}$ step for the dimerization direction on the upper terrace to be normal to the step edge, as shown in Fig. (2a). The binding energy of a pair surface $\mathrm{H}$ atoms on the lower terrace for -2 has the value of $-306 \mathrm{~kJ} / \mathrm{mol}$ greater than $-240 \mathrm{~kJ} / \mathrm{mol}$ of $\mathbf{M}_{1}(2-)$.

\section{REFERENCES}

[1] Siomi H, Tanabe K, Nishibayashi Y, Fujimori N. Epitaxial growth of high quality diamond film by the microwave plasma-assisted chemical vapor deposition method. Jpn J Appl Phys 1990; 29: 3440.

[2] Enckevort WJP, Janssen G, Vollenberg W, Schemer JJ, Giling LJ, Seal M. CVD diamond growth mechanisms as identified by surface topography. Diamond Relat Mater 1993; 2: 997-1003.

[3] Kobashi K. Diamond films: chemical vapor deposition for oriented and heteroepitaxial growth. Amsterdam: Elsevier 2005.

[4] Tsuno $T$, Imai $T$, Nishibayashi $Y$, Hamada $K$, Fujimori $N$. Epitaxially grown diamond (001) $2 \times 1 / 1 \times 2$ surface investigated by scanning tunneling microscopy in air. Jpn J Appl Phys 1991; 30: 1063-6.

[5] Lee N, Badzian A. A study of surface morphologies of (001) homoepitaxial diamond films. Diamond Relat Mater 1997; 6: 13045 . 
[6] Wang C, Irie M, Ito T. Growth and characterization of hillock-free high quality homoepitaxial diamond films. Diamond Relat Mater 2000; 9: 1650-4

[7] Kawarada H, Sasaki H, Sato A. Scanning-tunneling-microscope observation of the homoepitaxial diamond (001) $2 \times 1$ reconstruction observed under atmospheric pressure. Phys Rev 1995; B52: 113518.

[8] Tsuno T, Tomikawa T, Shikata S, Imai T, Fujimori N. diamond (001) single-domain $2 \times 1$ surface grown by chemical vapor deposition. Appl Phys Lett 1994; 64: 572-4.

[9] Yanagihara T. A model calculation of the homoepitaxial growth on diamond (111) surfaces by chemical vapor deposition. Jpn J Appl Phys 2004; 43: 287-92.

[10] Matsumoto O, Toshima H, Kanzaki Y. Effect of dilution gases in methane on the depotition of diamond-like carbon in a microwave discharge. Thin Solid Films 1985; 128: 341-51.

[11] Mhangru SP, Anderson AB. Adsorption and bonding of $\mathrm{C}_{1} \mathrm{H}_{\mathrm{x}}$ and $\mathrm{C}_{2} \mathrm{H}_{\mathrm{y}}$ on unreconstructed diamond (111). J Mater Res 1990; 5: 2286-95.
[12] Yanagihara T. Nucleation of diamond on $\{111\}$ surfaces of cubic boron nitride by CVD. Diamond Relat Mater 2004; 13: 616-21.

[13] Koizumi S, Inuzuka T. Initial growth process of epitaxial diamond thin films on cbn single crystals. Jpn J Appl Phys 1993; 32: 3920-7.

[14] Garrison BJ, Dawnkaski EJ, Srivastava D, Brenner DW. Molecular dynamics simulations of dimer opening on a diamond $\{001\}(2 \times 1)$ surface. Science 1992; 255: 835-8.

[15] Dewar MJS, Zoebisch EG, Healy EF, Stewart JJP. A new general purpose quantum mechanical molecular model. J Am Chem Soc 1985; 107: 3902-9.

[16] Stewart JJP. Optimization of parameters for semiempirical methods. J Comput Chem 1989; 10: 209-20.

[17] Harris SJ. Mechanism for diamond growth from methyl radicals Appl Phys Lett 1990; 56: 2298-300.

[18] Hoffmann R. Solids and surfaces: a chemist's view of bonding in extended structures. NewYork: VCH Publishers 1988.

[19] Chadi DJ. Stabilities of single-layer and bi-layer steps on si(001) surfaces. Phys Rev Lett 1987; 59: 1691-4.

(C) Yanagihara et al.; Licensee Bentham Open.

This is an open access article licensed under the terms of the Creative Commons Attribution Non-Commercial License (http://creativecommons.org/licenses/by-nc/ 3.0/) which permits unrestricted, non-commercial use, distribution and reproduction in any medium, provided the work is properly cited. 